\title{
ANALISIS PENINGKATAN KINERJA FTP SERVER MENGGUNAKAN LOAD BALANCING PADA CONTAINER
}

\author{
Januar Al Amien ${ }^{1}$, Doni Winarso ${ }^{2}$ \\ ${ }^{1}$ Teknik Informatika, Fakultas Ilmu Komputer, Universitas Muhammadiyah Riau \\ ${ }^{2}$ Sistem Informasi, Fakultas Ilmu Komputer, Universitas Muhammadiyah Riau \\ 1januaralamien@umri.ac.id, 2doniwinarso@umri.ac.id
}

\begin{abstract}
Cloud computing is a technology that answers the challenge of the need for efficient computing technology. There are many things that can be implemented using cloud computing technologies such as web services, storage services, applications and others. Use of cloud computing using container technology can help in the management of applications and optimize the use of resources in the form of memory and processor usage on the server. In this research docker containers implemented by service of FTP (File Transfer Protocol). The FTP service is made into 3 containers within a single server computer. To handle load problems performance on the FTP server against overload requests, load balancing is used. Load balancing is a method to improve performance while reducing the performance load on FTP servers. Based on the test results, the use of multi container and load balancing in the FTP server in load with two algorithm least connection and raound robin handling has result of smaller memory usage and utilization of processor usage evenly. Both algorithms are recommended for handling loads for FTP servers and will be more efficient when applied to servers with the same specifications and loads
\end{abstract}

Keywords: Cloud Computing, Docker, FTP, Load Balancing, HAProxy, Least Connection, Round

Robin.

\begin{abstract}
Abstrak
Cloud computing merupakan teknologi yang menjawab tantangan akan kebutuhan teknologi komputasi yang efisien. Terdapat banyak hal yang dapat diimplementasikan menggunakan teknologi cloud computing seperti web service, layanan penyimpanan, aplikasi dan lain-lain. Penerapan cloud computing dengan menggunakan teknologi container dapat membantu dalam pengelolaan aplikasi serta mengoptimalkan penggunaan sumber daya berupa penggunaan memory dan prosesor pada server. Dalam penelitian ini penerapan docker container diimplementasikan menggunakan layanan aplikasi FTP (File Transfer Protocol). Layanan FTP dibuat menjadi 3 container didalam satu computer server. Untuk menangani permasalahan beban kinerja pada FTP server terhadap permintaan yang terlalu berat (overload) digunakan load balancing. Load balancing merupakan metode untuk meningkatkan kinerja sekaligus mengurangi beban kinerja pada FTP server. Berdasarkan hasil pengujian, penerapan multi container serta load balancing didalam FTP server dalam penanganan beban dengan dua algortima least connection dan round robin memiliki hasil penggunaan memory yang lebih kecil dan pemanfaatan penggunaan prosesor yang merata kedua algoritma tersebut direkomendasikan untuk penanganan beban untuk ftp server dan akan lebih efisien apabila diterapkan pada server dengan spesifikasi dan beban yang sama.
\end{abstract}

Kata Kunci: Cloud Computing, Docker, FTP, Load Balancing, HAProxy, Least Connection, Round Robin .

\section{PENDAHULUAN}

Universitas Muhammadiyah Riau program studi Teknik Informatika, merupakan sebuah instansi yang memerlukan sebuah sistem penyimpanan data terpadu repositori file, untuk para dosen dengan menggunakan ftp yaitu protokol yang digunakan untuk mentransfer file dari satu host ke host lain [1].

protokol ini akan divirtualisasikan menjadi 3 server dalam satu server fisik, penerapan akan menggunkan aplikasi Docker Container untuk menangani virtual server dan sifatnya private, 
Private cloud merupakan sebuah mekanisme penyediaan resource IT secara menyeluruh, namun akan dideploy secara terpisah dari public cloud dan hanya bisa diakses melalui jaringan private, sehingga memiliki tingkat security yang lebih baik. Model ini cocok untuk perusahaan dengan skala enterprise yang sangat memperhatikan privasi dan keamanan data [2], dengan memanfaatkan sumber daya server yang di miliki oleh instansi menjadi solusi untuk mengatasi permasalah tersebut.

Docker container tidak seperti seperti Virtual mesin, Virtualisasi menciptakan versi virtual dari sebuah sistem atau sumber daya seperti penyimpanan, jaringan, dan OS dan lain-lain [3]. Dimana docker tidak menggunakan hardware atau virtualisasi. Program yang berjalan pada docker container berhubungan langsung dengan kernel linux pada host sistem operasi. Container memungkinkan mengisolasi lingkungan program, sehingga program dapat berjalan tanpa gangguan dari permasalahan di sistem operasi [4] .

Penerapan Load balancing dilakukan menggunakan haproxy untuk menangani kelebihan beban pada aplikasi, ketika beban tersebut menghabiskan seluruh resource yang ada, maka aplikasi akan mengalami kegagalan atau down [4]. Container memiliki keunggulan dari sisi kemudahkan deployment, maintenance, dan ringan, sehingga sangat mungkin untuk melakukan proses load balancing [4]. Fokus utama dalam penelitian ini Ada dua perbandingan algoritma yang akan di buat, algoritma Least Connection dan Round Robin. Dari kedua algoritma ini akan menjadi perbandingan untuk mengukur kinerja server container agar server bekerja dengan baik.

Dari data yang di dapat dari log, log ini akan membaca Context Switching adalah pertukaran proses pra-dieksekusi dari CPU dengan proses baru [5]. Dengan kata lain, pengalihan konteks adalah berapa kali proses mengalihkan eksekusi Algoritma penjadwalan dapat dioptimalkan dengan mengurangi waktu respons, respon time, waiting time dan dengan memaksimalkan CPU utilisation dan throughtput [5]. Log ini akan di peroses menggunakan Average waiting time untuk penghitungan rata respon time perbandingan algoritma Least Connection [6] dan
Round Robin dengan menghitung jumlah dari waktu tunggu di setiap proses.

Berdasarkan penelitian [7] Least Connection Scheduling Algorithm dan Enhanced Round Robin Algorithm hasil menunjukkan bahwa algoritma yang diusulkan bekerja lebih baik. Berdasarkan average procesing time (ms), dimana ada 3 data center, Throttled Load Balancer (TLB) DC1 0,383 ms, DC2 0,472 ms, DC3 0,552 ms. Least connection Scheduling algorithm (LCSA) DC1 0,369 ms, DC2 0,449 ms, DC3 0,537 ms. Enhanced Round Robin Algorithm (ERRA) DC1 0,355 ms, DC2 0426 $\mathrm{ms}$, DC3 0,517 ms.

Berdasarkan penelitian [8][9] kesimpulanya Round Robin, lebih baik untuk menyesuaikan menunggu rata-rata waktu yang diinginkan, perlihatkan pembagian waktu yang mewakili setiap proses dengan melakukan algoritma Round Robin dalam waktu kuantum yang berbeda nilainilai. Waktu kuantum memengaruhi hasil waktu tunggu rata-rata. Jika waktu kuantum lebih besar, Average Waiting Time akan menghasilkan nilai yang kecil, tetapi proses yang telah ada dalam antrian siap akan membutuhkan lebih banyak waktu untuk mendapatkan giliran. Algoritma Round Robin akan lebih efisien apabila diterapkan pada server dengan spesifikasi yang sama dan beban load yang juga sama[10]

\section{METODE PENELITIAN}

Berdasarkan gambar 4 dibawah Kerangka konseptual merupakan suatu bentuk kerangka berpikir yang dapat digunakan sebagai pendekatan ilmiah dalam memecahkan masalah yang menggambarkan hubungan antar variabel dalam proses analisis.

\section{Pengumpulan data}

Pengumpulan data adalah merupakan langkah awal dalam melakukan penelitian yang akan di teliti. Penelitian ini menggunakan teknik observasi, wawancara, dan studi literatur sebagai berikut:

2. Observasi

Teknik Observasi dilakukan untuk memperoleh data dengan cara mengamati secara langsung obyek yang berkaitan dengan kegiatan penelitian. Pada tahap ini peneliti melakukan pengamatan pada kegiatan penelitian terhadap kinerja container pada FTP server. 
3. Studi Pustaka

Pada tahap ini dilakukan dengan pengumpulan informasi yang diperlukan dalam tahap pembuatan perangkat lunak. Informasi yang diperlukan diperoleh dengan mempelajari jurnal penelitian dan buku maupun browsing internet yang berkaitan dengan Cloud Computing, Docker, dan FTP server.

4. Perancangan sistem

Topolology jaringan menggambarkan bentuk konsep komputer yang terhubung ke jaringan yang saling terkoneksi. Adapun bentuk rancangan topology jaringan pada penelitian yang akan dibuat seperti pada Gambar 5.

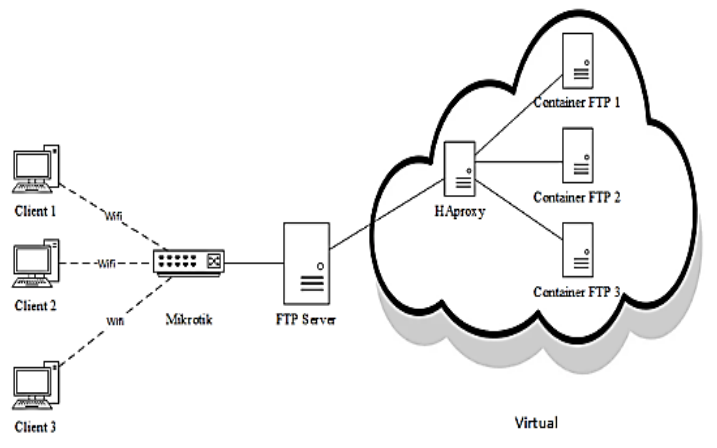

Gambar 2. Topologi Jaringan

Berdasarkan gambar 2, didalam FTP server terdapat 3 container FTP dan HAProxy digunakan sebagai balancer yang akan menangani proses load balancing. Dari ketiga user yang melakukan request terhadap FTP server, proses request tersebut akan dibagikan ke dalam 3 container FTP yang akan membuat penanganan request yang dilakukan oleh 3 user dibagi rata kedalam container FTP.

\section{Implementasi}

bertujuan untuk mengimplementasi sinkronisasi data pada setiap container dan Perhitungan berlanjut sampai proses terakhir. Ini menghasilkan total waktu tunggu dan akhirnya waktu tunggu rata-rata diperoleh [8]. Data ini merujuk kepada format $\log$ haproxy.txt di website haproxy, yang nantinya data ini sudah di kelompokan sesuai format log haproxy

\section{Skenario 1}

Gambar 3 Pengujian dilakukan dengan menggunakan 1 account user yang terdaftar pada 3 container FTP dan melakukan pengujian 3 percobaan login dan upload Video ukuran file
1,08GB, kedalam container FTP di lakukan pengamatan monitoring docker stats untuk baban CPU dan pemakaian memori dan Log file dari haproxy sebagai perbandingan Algoritma Least Connection dan Round Robin dihitung Average Waiting Time.

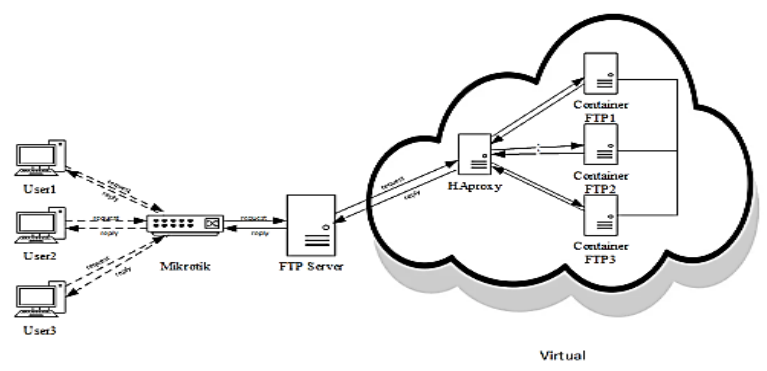

Gambar 3. Skenario 1 uplod Client Video

\section{Skenario 2}

Gambar 4 pengujian dilakukan dengan menggunakan 1 account user yang terdaftar pada 3 container FTP dan melakukan pengujian 3 percobaan login dan upload RAR ukuran file 1,78GB, kedalam container FTP di lakukan pengamatan monitoring docker stats untuk baban CPU dan pemakaian memori dan Log file dari haproxy sebagai perbandingan Algoritma Least Connection dan Round Robin dihitung Average Waiting Time.

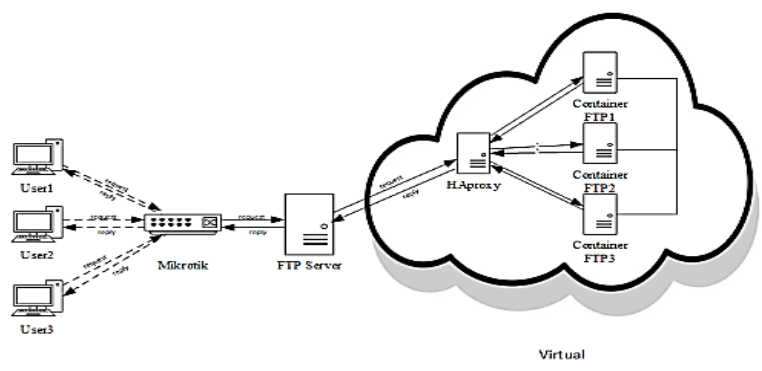

Gambar 4. Skenario 2 uplod Client File RAR

\section{Skenario 3}

Gambar 5 pengujian dilakukan dengan menggunakan 1 account user yang terdaftar pada 3 container FTP dan melakukan pengujian 3 percobaan login dan upload Document ukuran file $1,17 \mathrm{~GB}$, kedalam container FTP di lakukan pengamatan monitoring docker stats untuk baban CPU dan pemakaian memori dan Log file dari haproxy sebagai perbandingan Algoritma Least Connection dan Round Robin dihitung Average Waiting Time. 


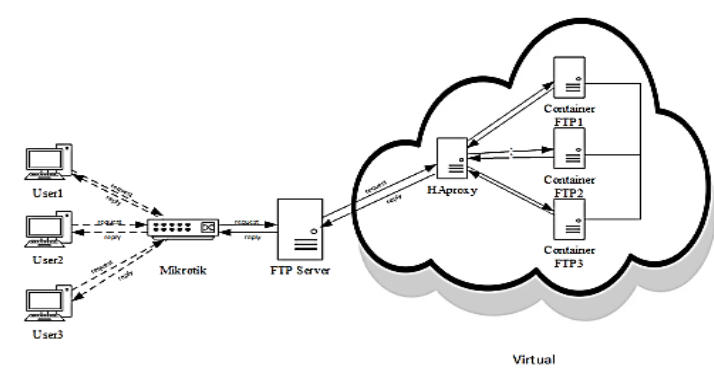

Gambar 5. Skenario 3 uplod Client File DO

\section{Skenario 4}

Gambar 6 pengujian dilakukan dengan menggunakan 1 account user yang terdaftar pada 3 container FTP dan melakukan pengujian 3 percobaan login dan upload PDF ukuran file 1,51GB, kedalam container FTP di lakukan monitoring docker stats untuk baban CPU dan pemakaian memori dan Log file dari haproxy sebagai perbandingan Algoritma Least Connection dan Round Robin dihitung Average Waiting Time.

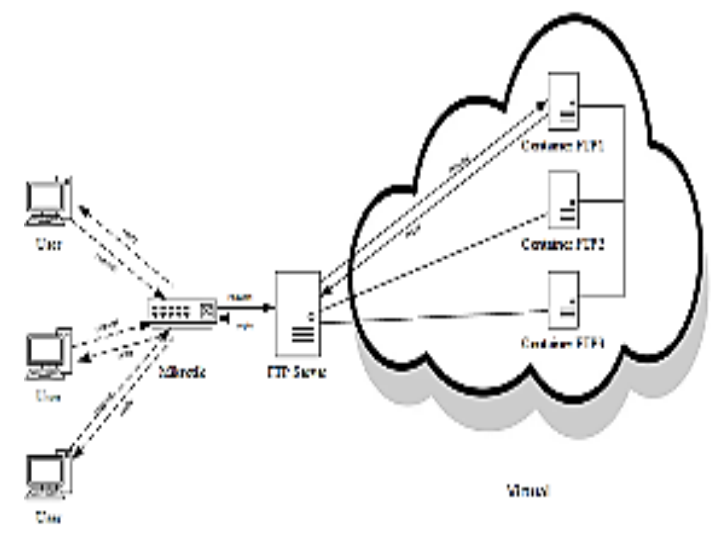

Gambar 6. Skenario 4 uplod Client File PDF

\section{Analisa}

Gambar 7 bertujuan mendapatkan hasil kinerja penggunaan CPU dan memory pada saat penanganan load balancing dengan menggunakan Algoritma Least Connection dan Round Robin dengan 1 user yang melakukan aktifitas upload file kedalam 3 server container FTP di lakukan pengamatan monitoring docker stats dan Log file dari haproxydengan melakukan 3 kali percobaan .

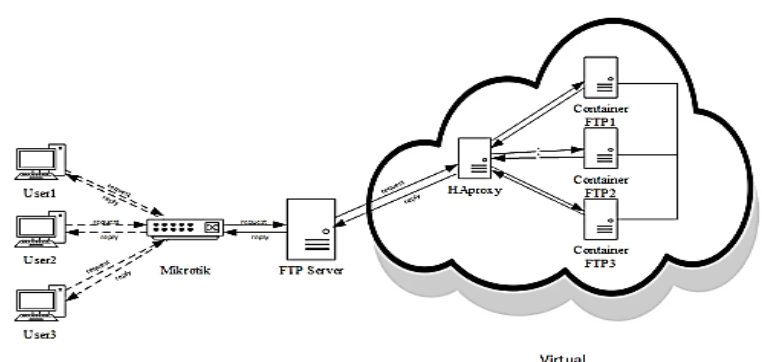

Gambar 7. Topology Skenario empat Pengujian Kinerja Load Balancing Container FTP

Untuk perhitungna Proses adalah, Waiting Time adalah WT [8].

$$
\begin{gathered}
T W T=\sum W T \\
A W T=\frac{T W T}{\text { Total Proses }}
\end{gathered}
$$

\section{HASIL DAN PEMBAHASAN}

Pada pengujian ini mengacu kepada skenario pengujian yang telah dirancang yang sudah di jelas kan di masing-masing skenario. Data diambil dari log haproxy data yang diambil untuk sample yaitu total Least Connection 5667, untuk Total Round Robin 5720 tota tercatat di log haproxy 11.387. Untuk Penghitungan rata-rata CPU dan Memory di lakukan pengamatan di docker stats.

Untuk mencari Avarage Waiting Time (AWT), terlebih dahulu jumlahkan Waiting Time (WT) adalah penjumlahan dari sama dengan "Total Time" (tt) adalah total waktu dalam milidetik yang terlewati antara penerimaan dan penutupan terakhir, Total Proses diambil dari jumlah "termination_state" adalah kondisi sesi ketika sesi berakhir Status sesi pada pemutusan. Total Time dan Termination_state di dapat dari format $\log$ haproxy.

$$
T W T=\sum W T
$$

$\mathrm{TWT}=\mathrm{WT} 1+\mathrm{WT} 2+\mathrm{WT} 3+. \mathrm{WTn}$

Total Waiting Time (TWT) di dapat dari pejumlahan dari Total Time (tt) sama dengan Waiting Time (WT) 
Nantinya kita dapat melihat dari hasil skenario yang telah dibuat berdasarkan urutan uploud file video, RAR, Doc dan PDF

\section{Pengujian Skenario satu}

Tabel 1. Average CPU Usage and memory Least Connection

\begin{tabular}{|c|c|c|c|c|}
\hline \multirow{2}{*}{ Percobaar } & \multicolumn{3}{|c|}{ CPU Usage } & \multirow{2}{*}{ Total } \\
\hline & s1 & s2 & s3 & \\
\hline Video 1 & $15,21 \%$ & $15,18 \%$ & & $15,20 \%$ \\
\hline Video 2 & & $19,60 \%$ & $15,27 \%$ & $17,44 \%$ \\
\hline Video 3 & $18,04 \%$ & $29,35 \%$ & & $23,70 \%$ \\
\hline Total & $16,63 \%$ & $21,38 \%$ & $15,27 \%$ & $18,78 \%$ \\
\hline \multirow{2}{*}{ Percobaan } & \multicolumn{3}{|c|}{ Memory Usage } & Total \\
\hline & s1 & s2 & s3 & \\
\hline Video 1 & $0,10 \%$ & $0,13 \%$ & $0,20 \%$ & $0,18 \%$ \\
\hline Video 2 & $0,17 \%$ & $0,23 \%$ & $0,14 \%$ & $0,19 \%$ \\
\hline Video 3 & $0,17 \%$ & $0,26 \%$ & $0,13 \%$ & $0,17 \%$ \\
\hline Total & $0,15 \%$ & $0,21 \%$ & $0,16 \%$ & $0,18 \%$ \\
\hline
\end{tabular}

Tabel 2. Average CPU Usage and memory Round Robin

\begin{tabular}{|c|c|c|c|c|}
\hline \multirow{2}{*}{$\begin{array}{c}\text { Percobaa } \\
n\end{array}$} & \multicolumn{3}{|c|}{ CPU Usage } & \multirow{2}{*}{ Total } \\
\hline & s1 & s2 & s3 & \\
\hline Video 1 & $\begin{array}{r}16,92 \\
\%\end{array}$ & & & $\begin{array}{r}22,10 \\
\%\end{array}$ \\
\hline Video 2 & $\begin{array}{r}14,92 \\
\%\end{array}$ & $\begin{array}{r}29,28 \\
\%\end{array}$ & & $\begin{array}{r}21,98 \\
\%\end{array}$ \\
\hline Video 3 & $\begin{array}{r}15,13 \\
\%\end{array}$ & & $\begin{array}{r}28,83 \\
\%\end{array}$ & $\begin{array}{r}24,59 \\
\%\end{array}$ \\
\hline Total & $\begin{array}{r}15,66 \\
\% \\
\end{array}$ & $\begin{array}{r}29,28 \\
\% \\
\end{array}$ & $\begin{array}{r}28,83 \\
\% \\
\end{array}$ & $\begin{array}{r}22,89 \\
\% \\
\end{array}$ \\
\hline Percobaa & \multicolumn{3}{|c|}{ Memory Usage } & Total \\
\hline $\mathrm{n}$ & s1 & s2 & s3 & 1 otal \\
\hline Video 1 & $0,31 \%$ & $0,33 \%$ & $0,22 \%$ & $0,27 \%$ \\
\hline Video 2 & $30 \%$ & $0,31 \%$ & $0,20 \%$ & $0,27 \%$ \\
\hline Video 3 & $30 \%$ & $0,30 \%$ & $0,20 \%$ & $0,27 \%$ \\
\hline Total & $0,30 \%$ & $0,31 \%$ & $0,21 \%$ & $0,27 \%$ \\
\hline
\end{tabular}

Tabel 3. Amount Total Time(ms) Least Connection

\begin{tabular}{|c|c|c|c|c|}
\hline \multirow{2}{*}{$\begin{array}{c}\text { Percobaa } \\
n\end{array}$} & \multicolumn{3}{|c|}{$\begin{array}{c}\text { Amount WaitingTime } \\
(\mathrm{ms}) \mathrm{tt}\end{array}$} & \multirow[t]{2}{*}{ TWT } \\
\hline & S1 & S2 & S3 & \\
\hline Video 1 & $\begin{array}{r}20492 \\
8\end{array}$ & $\begin{array}{r}10405 \\
3\end{array}$ & 70707 & 379688 \\
\hline Video 2 & 0 & $\begin{array}{r}10405 \\
9\end{array}$ & $\begin{array}{r}15084 \\
9\end{array}$ & 254908 \\
\hline Video 3 & $\begin{array}{r}16783 \\
4 \\
\end{array}$ & $\begin{array}{r}10404 \\
3 \\
\end{array}$ & 70262 & 342139 \\
\hline
\end{tabular}

Tabel 4. . Hitung termination_state sama dengan Total proses Least Connection

\begin{tabular}{|c|c|c|c|c|}
\hline \multirow{2}{*}{ Percobaan } & \multicolumn{3}{|c|}{ Hitung Proses } & \multirow{2}{*}{$\begin{array}{l}\text { Total } \\
\text { Proses }\end{array}$} \\
\hline & S1 & S2 & S3 & \\
\hline Video 1 & 3 & 2 & 2 & 7 \\
\hline Video 2 & 0 & 2 & 2 & 4 \\
\hline Video 3 & 3 & 2 & 1 & 6 \\
\hline
\end{tabular}

Tabel 5. Amount Time(ms) Round Robin

\begin{tabular}{|l|r|r|r|c|}
\hline \multirow{2}{*}{$\begin{array}{c}\text { Percobaa } \\
\mathrm{n}\end{array}$} & \multicolumn{3}{|c|}{ Amount WaitingTime } & \multirow{2}{*}{ TWT } \\
\cline { 2 - 4 } & \multicolumn{1}{|c|}{$\mathrm{S} 1$} & $\mathrm{~S} 2 \mathrm{tt}$ & $\mathrm{S} 3$ & \\
\hline \multirow{2}{*}{ Video 1 } & $\begin{array}{r}25694 \\
7\end{array}$ & 0 & 0 & 256947 \\
\hline \multirow{2}{*}{ Video 2 } & $\begin{array}{r}10403 \\
3\end{array}$ & $\begin{array}{r}18232 \\
8\end{array}$ & 63690 & 350051 \\
\hline Video 3 & $\begin{array}{r}30185 \\
8\end{array}$ & 0 & 33358 & \\
& & & & \\
\end{tabular}

Tabel 6. Hitung termination_state sama dengan Total proses Round Robin

\begin{tabular}{|l|r|r|r|r|}
\hline \multirow{2}{*}{ Percobaan } & \multicolumn{3}{|c|}{ Hitung Proses } & \multirow{2}{*}{ Total } \\
\cline { 2 - 4 } & S1 & \multicolumn{1}{|c|}{ S2 } & \multicolumn{1}{c|}{ S3 } & \multicolumn{1}{c|}{ Proses } \\
\hline Video 1 & 4 & 0 & 0 & 4 \\
\hline Video 2 & 2 & 4 & 1 & 7 \\
\hline Video 3 & 4 & 0 & 6 & 10 \\
\hline
\end{tabular}

\section{Pengujian Skenario dua}

Tabel 7. Average CPU Usage and memory Least Connection

\begin{tabular}{|l|c|c|c|c|}
\hline \multirow{2}{*}{ Percobaan } & \multicolumn{3}{|c|}{ CPU Usage } & \multirow{2}{*}{ Total } \\
\cline { 2 - 4 } & $\mathrm{s} 1$ & $\mathrm{~s} 2$ & $\mathrm{~s} 3$ & \\
\hline RAR 1 & & $28,83 \%$ & $14,45 \%$ & $21,64 \%$ \\
\hline RAR 2 & $15,40 \%$ & $28,74 \%$ & $16,50 \%$ & $20,21 \%$ \\
\hline RAR 3 & $29,52 \%$ & $30,24 \%$ & $25,85 \%$ & $28,54 \%$ \\
\hline Total & $22,46 \%$ & $29,27 \%$ & $18,93 \%$ & $23,46 \%$ \\
\hline \multirow{2}{*}{ Percobaan } & \multicolumn{3}{|c}{ Memory Usage } & \multirow{2}{*}{ Total } \\
\cline { 2 - 4 } & $\mathrm{s} 1$ & $\mathrm{~s} 2$ & $\mathrm{~s} 3$ & \\
\hline RAR 1 & $0,20 \%$ & $0,28 \%$ & $0,14 \%$ & $0,21 \%$ \\
\hline RAR 2 & $0,21 \%$ & $0,32 \%$ & $0,15 \%$ & $0,23 \%$ \\
\hline RAR 3 & $0,22 \%$ & $0,33 \%$ & $0,21 \%$ & $0,25 \%$ \\
\hline Total & $0,21 \%$ & $0,31 \%$ & $0,17 \%$ & $0,23 \%$ \\
\hline
\end{tabular}

Tabel 8. Average CPU Usage and memory Round Robin

\begin{tabular}{|c|r|r|r|r|}
\hline \multirow{2}{*}{$\begin{array}{c}\text { Percobaa } \\
\mathrm{n}\end{array}$} & \multicolumn{3}{|c|}{ CPU Usage } & \multirow{2}{*}{ Total } \\
\cline { 2 - 4 } RAR 1 & $\mathrm{s} 1$ & $\mathrm{~s} 2$ & $\mathrm{~s} 3$ & \\
\hline \multirow{2}{*}{ RA, } & $\begin{array}{r}15,24 \\
\%\end{array}$ & & 20,03 \\
& & & $\%$ \\
\hline
\end{tabular}


Volume 9 No. 3 | November 2019: 8 - 18

\begin{tabular}{|l|r|r|r|r|}
\hline \multirow{2}{*}{ RAR 2 } & $\begin{array}{r}30,64 \\
\%\end{array}$ & $\begin{array}{r}14,97 \\
\%\end{array}$ & $\begin{array}{r}14,48 \\
\%\end{array}$ & $\begin{array}{r}15,16 \\
\%\end{array}$ \\
\hline \multirow{2}{*}{ RAR 3 } & $\begin{array}{r}14,63 \\
\%\end{array}$ & $\begin{array}{r}14,89 \\
\%\end{array}$ & $\begin{array}{r}15,96 \\
\%\end{array}$ & $\begin{array}{r}16,72 \\
\%\end{array}$ \\
\hline \multirow{2}{*}{ Total } & $\begin{array}{r}19,92 \\
\%\end{array}$ & $\begin{array}{r}15,03 \\
\%\end{array}$ & $\begin{array}{r}15,22 \\
\%\end{array}$ & $\begin{array}{r}17,30 \\
\%\end{array}$ \\
\hline $\begin{array}{c}\text { Percobaa } \\
\mathrm{n}\end{array}$ & \multicolumn{3}{|c}{ Memory Usage } & \multirow{2}{*}{ Total } \\
\cline { 2 - 5 } & $\mathrm{s} 1$ & $\mathrm{~s} 2$ & $\mathrm{~s} 3$ & \multirow{2}{*}{ s2 } \\
\hline RAR 1 & $0,34 \%$ & $0,32 \%$ & $0,17 \%$ & $0,27 \%$ \\
\hline RAR 2 & $0,32 \%$ & $0,30 \%$ & $0,18 \%$ & $0,27 \%$ \\
\hline RAR 3 & $0,34 \%$ & $0,30 \%$ & $0,17 \%$ & $0,27 \%$ \\
\hline Total & $0,33 \%$ & $0,31 \%$ & $0,17 \%$ & $0,27 \%$ \\
\hline
\end{tabular}

Tabel 9. Amount Time(ms) Least Connection

\begin{tabular}{|c|c|c|c|c|}
\hline \multirow{2}{*}{$\begin{array}{c}\text { Percobaa } \\
\text { n }\end{array}$} & \multicolumn{3}{|c|}{$\begin{array}{c}\text { Amount WaitingTime } \\
\text { (ms) tt }\end{array}$} & \multirow{2}{*}{ TWT } \\
\cline { 2 - 4 } & S1 & S2 & S3 & \\
\hline RAR 1 & 85584 & $\begin{array}{c}20809 \\
1\end{array}$ & $\begin{array}{c}15807 \\
2\end{array}$ & 451747 \\
\hline RAR 2 & $\begin{array}{c}16308 \\
4\end{array}$ & $\begin{array}{c}10409 \\
5\end{array}$ & $\begin{array}{c}18329 \\
2\end{array}$ & 450471 \\
\hline RAR 3 & $\begin{array}{c}10405 \\
2\end{array}$ & $\begin{array}{c}23657 \\
8\end{array}$ & $\begin{array}{c}10903 \\
9\end{array}$ & 449669 \\
\hline
\end{tabular}

Tabel 10. Hitung termination_state sama dengan Total proses Least Connection

\begin{tabular}{|l|r|r|r|r|}
\hline \multirow{2}{*}{ Percobaan } & \multicolumn{3}{|c|}{ Total Proses } & \multirow{2}{*}{ Total } \\
\cline { 2 - 4 } & \multicolumn{1}{|c|}{ S1 } & \multicolumn{1}{|c|}{ S3 } & \multicolumn{1}{c|}{ Proses } \\
\hline RAR 1 & 2 & 4 & 3 & 9 \\
\hline RAR 2 & 3 & 2 & 4 & 9 \\
\hline RAR 3 & 2 & 5 & 2 & 9 \\
\hline
\end{tabular}

Tabel 11. Amount Time(ms) Round Robin

\begin{tabular}{|l|r|r|r|r|}
\hline \multirow{2}{*}{$\begin{array}{c}\text { Percobaa } \\
\text { n }\end{array}$} & \multicolumn{4}{|c|}{$\begin{array}{c}\text { Amount WaitingTime } \\
\text { (ms) tt }\end{array}$} \\
\cline { 2 - 4 } & S1 & \multicolumn{1}{|c|}{ S2 } & S3 & \\
\hline \multirow{2}{*}{ RAR 1 } & 0 & 10403 & & \\
& 0 & 3 & 78864 & 182897 \\
\hline \multirow{2}{*}{ RAR 2 } & 18310 & 10403 & 16192 & \\
& 3 & 4 & 7 & 449064 \\
\hline \multirow{2}{*}{ RAR 3 } & 10404 & 18218 & 16205 & \\
& 0 & 3 & 0 & 448273 \\
\hline
\end{tabular}

Tabel 12. Hitung termination_state sama dengan Total proses Round Robin

\begin{tabular}{|l|r|r|r|r|}
\hline \multirow{2}{*}{ Percobaan } & \multicolumn{3}{|c|}{ Hitung Proses } & \multirow{2}{*}{ Total } \\
\cline { 2 - 4 } & \multicolumn{1}{|c|}{ S1 } & \multicolumn{1}{|c|}{ S2 } & \multicolumn{1}{c|}{ S3 } & \multicolumn{1}{c|}{ Proses } \\
\hline RAR 1 & 0 & 2 & 2 & 4 \\
\hline RAR 2 & 4 & 2 & 3 & 9 \\
\hline RAR 3 & 2 & 4 & 3 & 9 \\
\hline
\end{tabular}

Pengujian Skenario tiga

Tabel 13. Average CPU Usage and memory Least Connection

\begin{tabular}{|c|c|c|c|c|}
\hline \multirow{2}{*}{ Percobaan } & \multicolumn{3}{|c|}{ CPU Usage } & \multirow{2}{*}{ Total } \\
\cline { 2 - 4 } & $\mathrm{s} 1$ & $\mathrm{~s} 2$ & $\mathrm{~s} 3$ & \\
\hline DOC 1 & $8,58 \%$ & & $15,20 \%$ & $11,89 \%$ \\
\hline DOC 2 & $14,80 \%$ & & $7,34 \%$ & $11,07 \%$ \\
\hline DOC 3 & $8,65 \%$ & $13,76 \%$ & & $11,21 \%$ \\
\hline Total & $10,68 \%$ & $13,76 \%$ & $11,27 \%$ & $11,39 \%$ \\
\hline \multirow{2}{*}{ Percobaan } & \multicolumn{3}{|c|}{ Memory Usage } & \multirow{2}{*}{ Total } \\
\cline { 2 - 4 } & $\mathrm{s} 1$ & $\mathrm{~s} 2$ & $\mathrm{~s} 3$ & \\
\hline DOC 1 & $0,27 \%$ & $0,35 \%$ & $0,21 \%$ & $0,28 \%$ \\
\hline DOC 2 & $0,28 \%$ & $0,36 \%$ & $0,24 \%$ & $0,29 \%$ \\
\hline DOC 3 & $0,37 \%$ & $31,00 \%$ & $0,25 \%$ & $10,54 \%$ \\
\hline Total & $0,31 \%$ & $10,57 \%$ & $0,23 \%$ & $3,70 \%$ \\
\cline { 5 - 5 } & & & \\
\hline
\end{tabular}

Tabel 14. CPU Usage and memory Round Robin

\begin{tabular}{|l|r|r|r|c|}
\hline \multirow{2}{*}{$\begin{array}{c}\text { Percobaa } \\
\mathrm{n}\end{array}$} & \multicolumn{3}{|c|}{ CPU Usage } & \multirow{2}{*}{ Total } \\
\cline { 2 - 4 } DOC 1 & $\mathrm{~s} 1$ & $\mathrm{~s} 24,66$ & $\mathrm{~s} 3$ & \\
& $\%$ & & & \multirow{2}{*}{$16,14 \%$} \\
\hline DOC 2 & $\begin{array}{r}16,14 \\
\%\end{array}$ & & & $18,31 \%$ \\
\hline \multirow{2}{*}{ DOC 3 } & $\begin{array}{r}18,31 \\
\%\end{array}$ & & & $6,57 \%$ \\
\hline Total & $\begin{array}{r}19,70 \\
\%\end{array}$ & $\begin{array}{r}0,00 \\
\%\end{array}$ & $\begin{array}{r}0,00 \\
\%\end{array}$ & $13,67 \%$ \\
\hline Percobaa \\
$\mathrm{n}$
\end{tabular}

Tabel 15. Amount Time(ms) Least Connection

\begin{tabular}{|c|c|c|c|c|}
\hline \multirow{2}{*}{$\begin{array}{c}\text { Percobaa } \\
\mathrm{n}\end{array}$} & \multicolumn{3}{|c|}{ Amount WaitingTime (ms) } & \multirow{2}{*}{ TWT } \\
\cline { 2 - 4 } & $\mathrm{S} 1$ & $\mathrm{~S} 2$ & $\mathrm{~S} 3$ & \\
\hline \multirow{2}{*}{ DOC 1} & $\begin{array}{c}15534 \\
4\end{array}$ & 0 & $\begin{array}{c}28222 \\
2\end{array}$ & $\begin{array}{c}43756 \\
6\end{array}$ \\
\hline \multirow{2}{*}{ DOC 2} & $\begin{array}{c}26136 \\
0\end{array}$ & 54063 & $\begin{array}{c}26243 \\
7\end{array}$ & $\begin{array}{c}57786 \\
0\end{array}$ \\
\hline \multirow{2}{*}{ DOC 3 } & $\begin{array}{c}10149 \\
6\end{array}$ & 161306 & 0 & 26280 \\
\hline
\end{tabular}


Tabel 16. Hitung termination_state sama dengan Total proses Least Connection

\begin{tabular}{|l|r|r|r|r|}
\hline \multirow{2}{*}{ Percobaan } & \multicolumn{3}{|c|}{ Count Proses } & \multirow{2}{*}{ Total } \\
\cline { 2 - 4 } & \multicolumn{1}{|c|}{ S1 } & \multicolumn{1}{|c|}{ S2 } & \multicolumn{1}{c|}{ S3 } & \multicolumn{1}{c}{ Proses } \\
\hline DOC 1 & 53 & 0 & 47 & 100 \\
\hline DOC 2 & 49 & 1 & 49 & 99 \\
\hline DOC 3 & 49 & 50 & 0 & 99 \\
\hline
\end{tabular}

Tabel 17. Amount Time(ms) Round Robin

\begin{tabular}{|l|c|r|r|c|}
\hline \multirow{2}{*}{$\begin{array}{c}\text { Percobaa } \\
\mathrm{n}\end{array}$} & \multicolumn{3}{|c|}{$\begin{array}{c}\text { Amount WaitingTime } \\
(\mathrm{ms}) \mathrm{tt}\end{array}$} & \multirow{2}{*}{ TWT } \\
\cline { 2 - 5 } & \multicolumn{1}{|c|}{$\mathrm{S} 1$} & $\mathrm{~S} 2$ & \multicolumn{1}{c|}{$\mathrm{S} 3$} & Waktu \\
\hline \multirow{2}{*}{ DOC 1} & 199515 & 5429 & 5403 & \\
& & 9 & 9 & 307853 \\
\hline DOC 2 & 202319 & 0 & 0 & 256609 \\
\hline DOC 3 & & & & 107187 \\
& 1071879 & 0 & 0 & 9 \\
\hline
\end{tabular}

Tabel 18. Hitung termination_state sama dengan Total proses Round Robin

\begin{tabular}{|l|r|r|r|r|}
\hline \multirow{2}{*}{ Percobaan } & \multicolumn{3}{|c|}{ Hitung Proses } & \multirow{2}{*}{ Total } \\
\cline { 2 - 4 } & S1 & \multicolumn{1}{|c|}{ S2 } & \multicolumn{1}{c|}{ S3 } & \multicolumn{1}{c|}{ Proses } \\
\hline DOC 1 & 96 & 1 & 1 & 98 \\
\hline DOC 2 & 96 & 0 & 1 & 97 \\
\hline DOC 3 & 98 & 0 & 0 & 98 \\
\hline
\end{tabular}

\section{Pengujian Skenario empat}

Tabel 19. CPU Usage and memory Least Connecti

\begin{tabular}{|c|c|c|c|c|}
\hline \multirow{2}{*}{ Percobaan } & \multicolumn{3}{|c|}{ CPU Usage } & \multirow{2}{*}{ Total } \\
\cline { 2 - 4 } & $\mathrm{s} 1$ & $\mathrm{~s} 2$ & $\mathrm{~s} 3$ & \\
\hline PDF1 & & $8,86 \%$ & $8,85 \%$ & $8,86 \%$ \\
\hline PDF2 & & $8,51 \%$ & $7,48 \%$ & $8,00 \%$ \\
\hline PDF3 & & $8,16 \%$ & $8.03 \%$ & $8,16 \%$ \\
\hline Total & $0,00 \%$ & $8,51 \%$ & $8,17 \%$ & $8,34 \%$ \\
\hline \multirow{2}{*}{ Percobaan } & \multicolumn{2}{|c|}{ Memory Usage } & \multirow{2}{*}{ Total } \\
\cline { 2 - 4 } & s1 & s2 & s3 & \\
\hline PDF1 & $0,32 \%$ & $0,40 \%$ & $0,40 \%$ & $0,37 \%$ \\
\hline PDF2 & $0,33 \%$ & $0,43 \%$ & $0,31 \%$ & $0,36 \%$ \\
\hline PDF3 & $0,27 \%$ & $0,34 \%$ & $0,29 \%$ & $0,30 \%$ \\
\hline Total & $0,31 \%$ & $0,39 \%$ & $0,33 \%$ & $0,34 \%$ \\
\hline
\end{tabular}

Tabel 20. CPU Usage and memory Round Robin

\begin{tabular}{|l|l|r|r|r|}
\hline \multirow{2}{*}{$\begin{array}{c}\text { Percobaa } \\
\mathrm{n}\end{array}$} & \multicolumn{3}{|c|}{ CPU Usage } & \multirow{2}{*}{ Total } \\
\cline { 2 - 4 } & $\mathrm{s} 1$ & $\mathrm{~s} 2$ & $\mathrm{~s} 3$ & \\
\hline PDF1 & & $\begin{array}{r}8,45 \\
\%\end{array}$ & $\begin{array}{r}8,35 \\
\%\end{array}$ & $9,57 \%$ \\
\hline PDF2 & & $\begin{array}{r}9,87 \\
\%\end{array}$ & $\begin{array}{r}9,27 \\
\%\end{array}$ & $8,27 \%$ \\
\hline
\end{tabular}

\begin{tabular}{|c|c|c|c|c|}
\hline PDF3 & & $\begin{array}{r}8,22 \\
\% \\
\end{array}$ & $\begin{array}{r}8,32 \\
\% \\
\end{array}$ & $5,83 \%$ \\
\hline Total & 0,00 & 8,85 & 8,65 & $780 \%$ \\
\hline Percobaa & \multicolumn{3}{|c|}{ Memory Usage } & \multirow{2}{*}{ Total } \\
\hline $\mathrm{n}$ & s1 & s2 & s3 & \\
\hline PDF1 & $\begin{array}{r}0,30 \\
\%\end{array}$ & $\begin{array}{r}0,34 \\
\%\end{array}$ & $\begin{array}{r}0,19 \\
\%\end{array}$ & $0.29 \%$ \\
\hline PDF2 & $\begin{array}{r}0,30 \\
\%\end{array}$ & $\begin{array}{r}0,35 \\
\%\end{array}$ & $\begin{array}{r}0,21 \\
\%\end{array}$ & $0.29 \%$ \\
\hline PDF3 & $\begin{array}{r}0,30 \\
\%\end{array}$ & $\begin{array}{r}0,35 \\
\%\end{array}$ & $\begin{array}{r}0,21 \\
\%\end{array}$ & $0,28 \%$ \\
\hline Total & $\begin{array}{r}0,30 \\
\%\end{array}$ & $\begin{array}{r}0,35 \\
\%\end{array}$ & $\begin{array}{r}0,20 \\
\%\end{array}$ & $0,29 \%$ \\
\hline
\end{tabular}

Tabel 21. Amount Time(ms) Least Connection

\begin{tabular}{|c|c|c|c|c|}
\hline $\begin{array}{c}\text { Percobaa } \\
\mathrm{n}\end{array}$ & \multicolumn{3}{|c|}{ Amount Time $(\mathrm{ms}) \mathrm{t}$} & \multirow{2}{*}{ TWT } \\
\cline { 2 - 4 } PDF1 & $\mathrm{S} 1$ & $\mathrm{~S} 2$ & $\mathrm{~S} 3$ & \\
\hline PDF2 & 0 & $\begin{array}{c}30176 \\
1\end{array}$ & $\begin{array}{c}30102 \\
3\end{array}$ & 602784 \\
\hline PDF3 & $\begin{array}{c}30036 \\
9\end{array}$ & $\begin{array}{c}30292 \\
9\end{array}$ & $\begin{array}{c}30321 \\
3\end{array}$ & 660208 \\
\hline
\end{tabular}

Tabel 22. Hitung termination_state sama dengan Total proses Least Connection

\begin{tabular}{|l|r|r|r|r|}
\hline \multirow{2}{*}{ Percobaan } & \multicolumn{3}{|c|}{ Hitung Proses } & \multirow{2}{*}{ Total Proses } \\
\cline { 2 - 4 } & S1 & \multicolumn{1}{|c|}{ S2 } & \multicolumn{1}{c|}{ S3 } & \\
\hline PDF1 & 0 & 893 & 894 & 1787 \\
\hline PDF2 & 1 & 894 & 891 & 1786 \\
\hline PDF3 & 876 & 1 & 875 & 1752 \\
\hline
\end{tabular}

Tabel 23. Amount Time(ms) Round Robin

\begin{tabular}{|c|c|c|c|c|}
\hline \multirow{2}{*}{$\begin{array}{c}\text { Percobaa } \\
n\end{array}$} & \multicolumn{3}{|c|}{$\begin{array}{l}\text { Amount WaitingTime } \\
(\mathrm{ms}) \mathrm{tt}\end{array}$} & \multirow{2}{*}{$\begin{array}{c}\text { TWT } \\
\text { Waktu } \\
\end{array}$} \\
\hline & S1 & S2 & S3 & \\
\hline PDF1 & 0 & $\begin{array}{c}16422 \\
7\end{array}$ & $\begin{array}{c}16702 \\
0\end{array}$ & 331247 \\
\hline PDF2 & $\begin{array}{c}5664 \\
4\end{array}$ & $\begin{array}{c}11143 \\
7\end{array}$ & $\begin{array}{c}11130 \\
7\end{array}$ & 279388 \\
\hline PDF3 & 0 & $\begin{array}{c}10881 \\
2\end{array}$ & $\begin{array}{c}10891 \\
9\end{array}$ & 217731 \\
\hline
\end{tabular}

Tabel 24. Hitung termination_state sama dengan Total proses Round Robin

\begin{tabular}{|l|r|r|r|r|}
\hline \multirow{2}{*}{ Percobaan } & \multicolumn{3}{|c|}{ Count Proses } & \multirow{2}{*}{ Total } \\
& \multicolumn{1}{|c|}{ S1 } & \multicolumn{1}{|c|}{ S2 } & \multicolumn{1}{c|}{ S3 } & \multicolumn{1}{c|}{ Proses } \\
\hline DOC 1 & 96 & 1 & 1 & 98 \\
\hline PDF1 & 0 & 897 & 898 & 1795 \\
\hline PDF2 & 1 & 896 & 897 & 1794 \\
\hline
\end{tabular}


Volume 9 No. 3 | November 2019: 8 - 18

\begin{tabular}{|l|l|l|l|l|}
\hline PDF3 & 0 & 898 & 897 & 1795 \\
\hline
\end{tabular}

Pengujian Avarge Waiting Time Least Connection dan Round Robin

Pada pengujian menghitung rata-rata waktu tunggu satu proses dapat dihitung :

$$
A W T=\frac{T W T}{\text { Total Proses }}
$$

Dari total pejumlahan Waiting Time WT dan total proses di hitung berapa kali total WT memproses maka di dapat Total Average Waiting Time.

Tabel 25. Average Waiting Time Least Connection

\begin{tabular}{|l|r|r|r|r|}
\hline $\begin{array}{c}\text { Percobaan } \\
\text { File }\end{array}$ & \multicolumn{1}{c|}{ S1 } & \multicolumn{1}{c|}{ S2 } & \multicolumn{1}{c|}{ S3 } & \multicolumn{1}{c|}{ AWT } \\
\hline Video 1 & 68309 & 0 & 0 & 54241 \\
\hline Video 2 & 0 & 52030 & 75425 & 63727 \\
\hline Video 3 & 55945 & 0 & 70262 & 57023 \\
\hline Total & 41418 & 17343 & 48562 & 58330 \\
\hline RAR 1 & 0 & 52023 & 52691 & 50194 \\
\hline RAR 2 & 54361 & 52048 & 45823 & 50052 \\
\hline RAR 3 & 52026 & 47316 & 54520 & 49963 \\
\hline Total & 35462 & 50462 & 51011 & 50070 \\
\hline DOC 1 & 2931 & 0 & 6005 & 4376 \\
\hline DOC 2 & 5334 & 0 & 5356 & 5837 \\
\hline DOC 3 & 2071 & 0 & 0 & 2655 \\
\hline Total & 3445 & 0 & 3787 & 4289 \\
\hline PDF1 & 0 & 338 & 337 & 337 \\
\hline PDF2 & 54066 & 339 & 340 & 370 \\
\hline PDF3 & 0 & 54078 & 344 & 374 \\
\hline Total & 18022 & 18252 & 340 & 1081 \\
\hline
\end{tabular}

Pengujian Avarge Waiting Time Round Robin Tabel 26. Average Waiting Time Round Robin

\begin{tabular}{|l|r|r|r|r|}
\hline $\begin{array}{l}\text { Percobaan } \\
\text { File }\end{array}$ & \multicolumn{1}{c|}{ S1 } & \multicolumn{1}{c|}{ S2 } & \multicolumn{1}{c|}{ S3 } & \multicolumn{1}{l|}{ AWT } \\
\hline Video 1 & 64237 & 0 & 0 & 64237 \\
\hline Video 2 & 52017 & 45582 & 63690 & 50007 \\
\hline Video 3 & 75465 & 0 & 55598 & 63545 \\
\hline Total & 63906 & 15194 & 39763 & 59263 \\
\hline RAR 1 & 0 & 52017 & 39432 & 45724 \\
\hline RAR 2 & 45776 & 52017 & 53976 & 49896 \\
\hline RAR 3 & 52020 & 45546 & 54017 & 49808 \\
\hline Total & 32599 & 49860 & 49141 & 48476 \\
\hline DOC 1 & 2078 & 54299 & 54039 & 3141 \\
\hline DOC 2 & 2107 & 0 & 54290 & 2645 \\
\hline DOC 3 & 10938 & 0 & 0 & 10938 \\
\hline Total & 5041 & 18100 & 36110 & 5575 \\
\hline PDF1 & 0 & 183 & 186 & 185 \\
\hline PDF2 & 56644 & 124 & 124 & 156 \\
\hline
\end{tabular}

\begin{tabular}{|l|r|r|r|r|} 
PDF3 & 0 & 121 & 121 & 121 \\
\hline Total & 18881 & 143 & 144 & 462 \\
\hline
\end{tabular}

\section{Hasil grafik CPU dan memory dari masing- masing skenario}

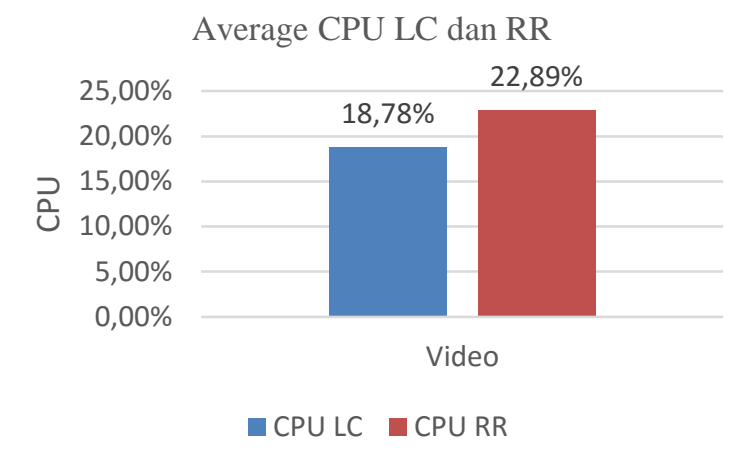

Gambar 8. Hasil Video Perbandingan CPU Least Connection dan Round Robin

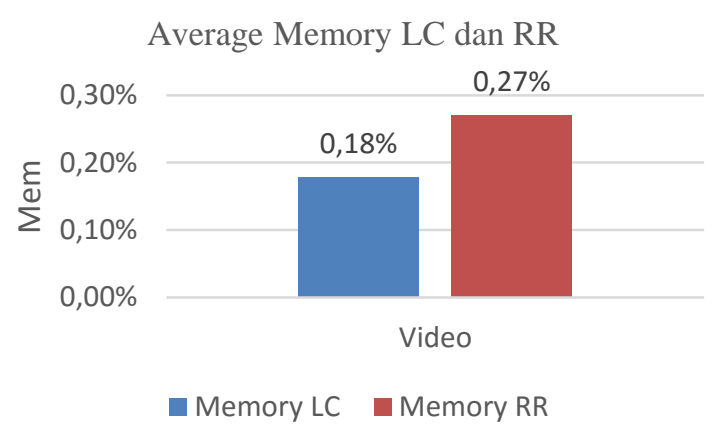

Gambar 9. Hasil Video Perbandingan Memori Least Connection dan Round Robin

Berdasarkan gambar 8 dan 9 dapat di hasilkan skenario 1 beban pada cpu least connection $18,78 \%$ dan round robin $22,89 \%$, dan pemakaian memory least connection $0,18 \%$ dan round Robin $0,27 \%$ ketika client uplod video ke 3 server virtual container dalam 3 kali percobaan.

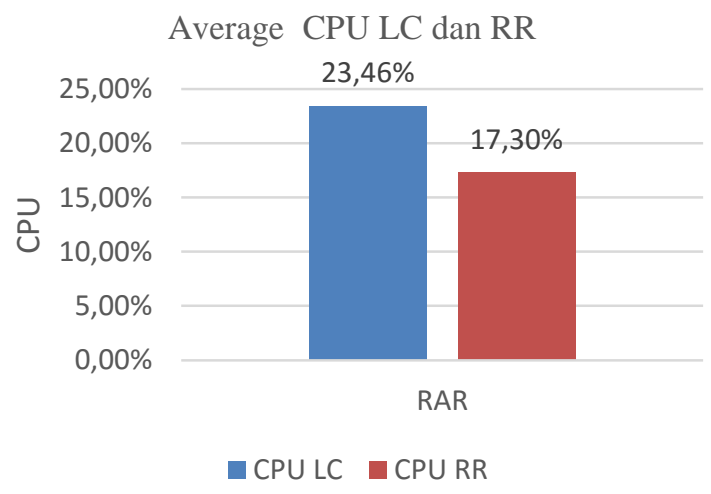

Gambar 10. Hasil Video Perbandingan CPU Least Connection dan Round Robin 


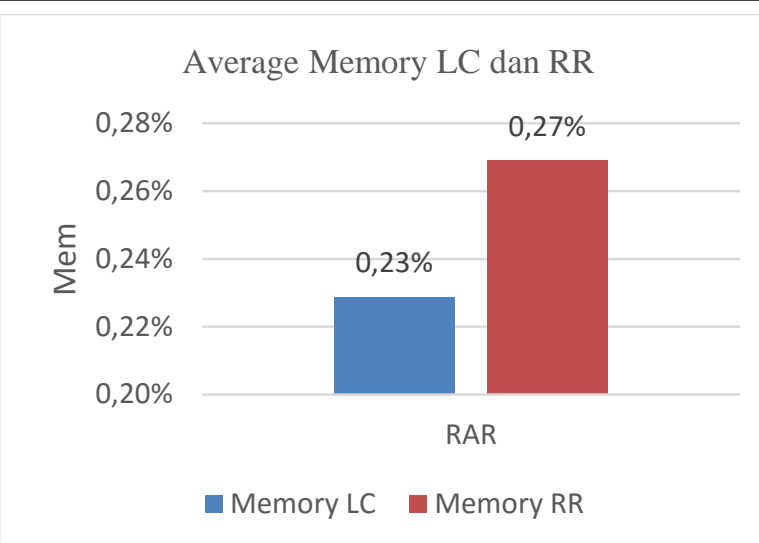

Gambar 11. Hasil Video Perbandingan Memori Least Connection dan Round Robin

Berdasarkan gambar 10 dan 11 dapat di hasilkan skenario 1 beban pada cpu least connection $23,46 \%$ dan round robin $17,30 \%$, dan pemakaian memoryleast connection $0,23 \%$ dan round Robin 0,27\% ketika client uplod RAR ke 3 server virtual container dalam 3 kali percobaan.

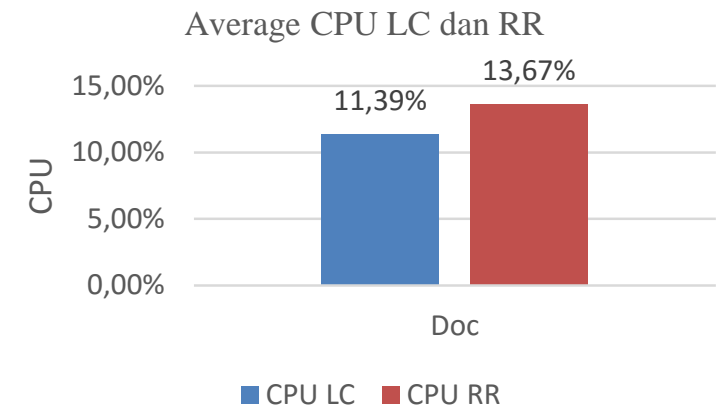

Gambar 12. Hasil Video Perbandingan CPU Least Connection dan Round Robin

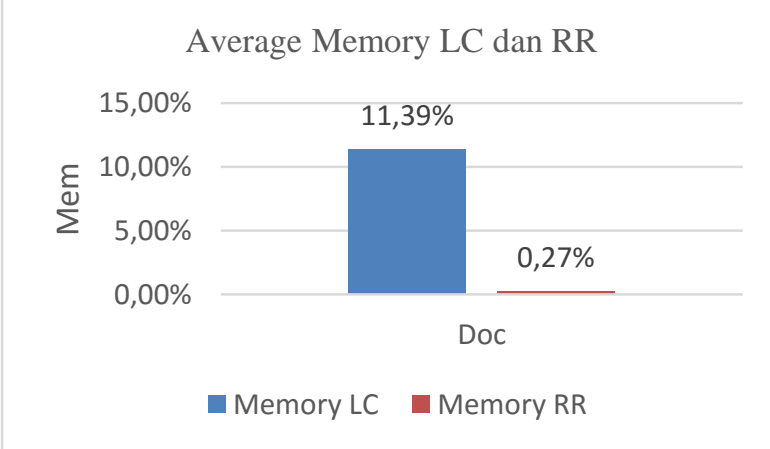

Gambar 13. Hasil Video Perbandingan Memori Least Connection dan Round Robin

Berdasarkan gambar 12 dan 13 dapat di hasilkan skenario 1 beban pada cpu least connection $11,39 \%$ dan round robin $13,67 \%$, dan pemakaian memoryleast connection $11,39 \%$ dan round
Robin 0,27\% ketika client uplod DOC ke 3 server virtual container dalam 3 kali percobaan.

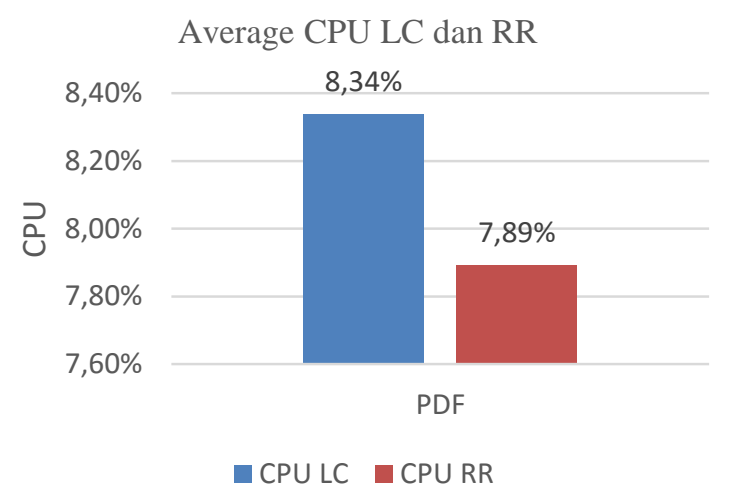

Gambar 14. Hasil Video Perbandingan CPU Least Connection dan Round Robin

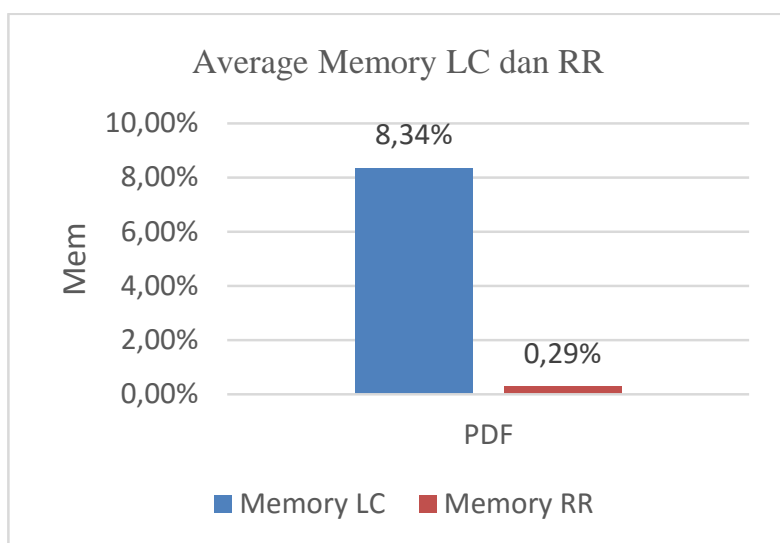

Gambar 15. Hasil Video Perbandingan Memori Least Connection dan Round Robin

Berdasarkan gambar 14 dan 15 dapat di hasilkan skenario 1 beban pada cpu least connection $8,34 \%$ dan round robin $7,89 \%$, dan pemakaian memoryleast connection $8,34 \%$ dan round Robin $0,29 \%$ ketika client uplod PDF ke 3 server virtual container dalam 3 kali percobaan.

\section{Hasil grafik Average Waiting Time Least Connection Dan Round Robin dari masing- masing skenario}

\section{Total Avarage Waiting Time}

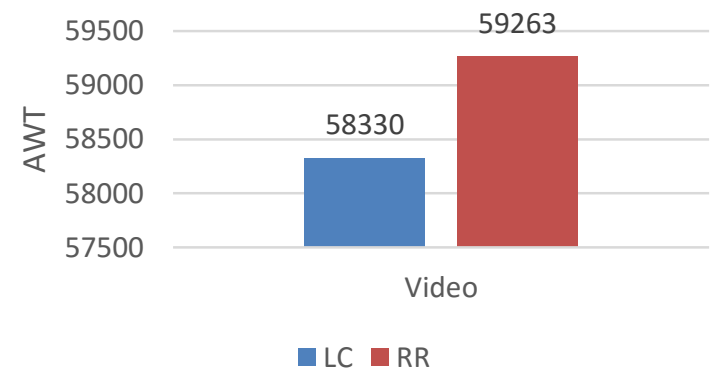


Gambar 16. Hasil Video Perbandingan Avarge Waiting Time

Pada gambar 16 grafik total Avarege Waiting Time ada peningkatan pada round robin yaitu $59263 \mathrm{~ms}$ sedangkan least connection $58330 \mathrm{~ms}$, ketika client uploud file video ke 3 server container.

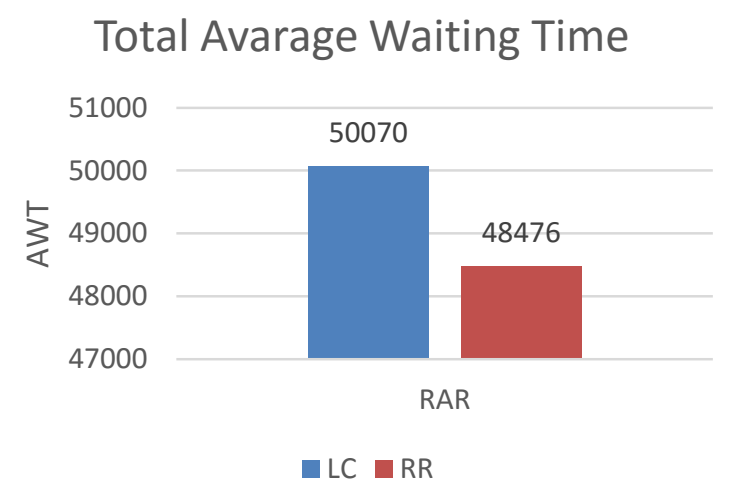

Gambar 17. Hasil RAR Perbandingan Avarge Waiting Time

Pada gambar 17 grafik total Avarege Waiting Time ada peningkatan pada least connection yaitu 50070ms sedangkan Round Robin $48476 \mathrm{~ms}$, ketika client uploud file RAR ke 3 server container.

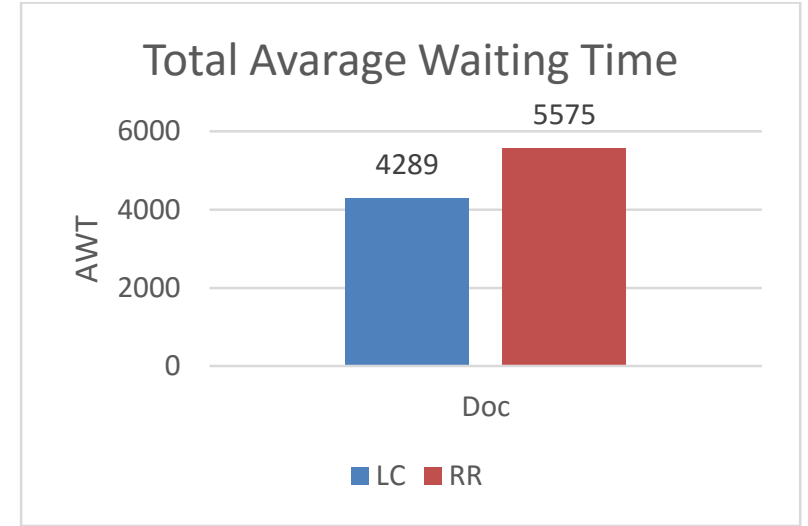

Gambar 18. Hasil DOC Perbandingan Avarge Waiting Time

Pada gambar 18 grafik total Avarege Waiting Time ada peningkatan pada round robin yaitu $5575 \mathrm{~ms}$ sedangkan least connection $4289 \mathrm{~ms}$, ketika client uploud file DOC ke 3 server container

\section{Total Avarage Waiting Time}

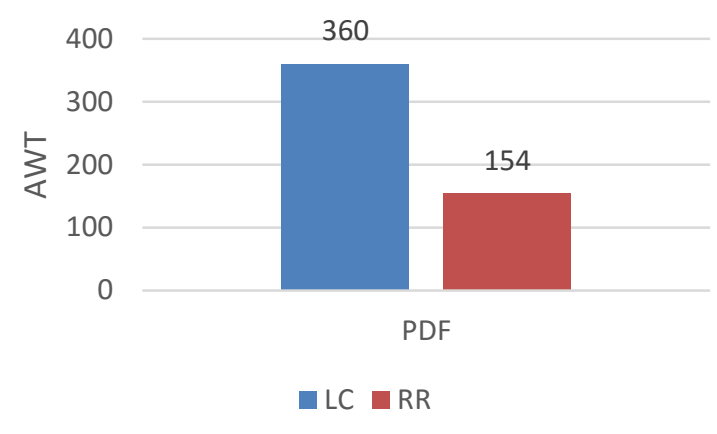

Gambar 19. Hasil DOC Perbandingan Avarge Waiting Time

Pada gambar 19 grafik total Avarege Waiting Time ada peningkatan pada least connection yaitu $360 \mathrm{~ms}$ sedangkan least connection $154 \mathrm{~ms}$, ketika client uploud file video ke 3 server container

\section{KESIMPULAN DAN SARAN}

Berdasarkan hasil yang diperoleh melalui pengamatan dan ujicoba, maka dapat ditarik kesimpulan sebagai berikut:

1. Penerapan server FTP pada Universitas Muhammadiyah Riau program studi Teknik Informatika membantu dalam memenuhi kebutuhan Dosen akan penyimpanan data yang terpusat, dikarenakan masing-masing dosen memiliki akses kedalam sesuai dengan akun masing-masing tanpa tercapur dengan yang lain.

2. Penerapan load balancing dapat mengalihkan service yang mati ke service yang lain, sehingga proses pengiriman data tidak terganggu dikarenakan service yang mati.

3. Penerapan multi container dan balancing pada server FTP membantu mengoptimalkan kinerja pada server FTP dalam penanganan request atau beban yang banyak dan mampu membagi kerja pada setiap container untuk menjaga kestabilan memory dan prosesor yang tetap membuat sistem berjalan baik.

4. Perbandingan dua algoritma least connection dan Round Robin tidak terlalu jauh dari beban CPU dan Pemakaian Memori, begitu juga waktu di bagi dengan proses, algoritma least connection dan Round Robin kedua algortima tergantung kecepatan proses pada beban proses tersebut direkomendasikan untuk penanganan beban untuk ftp server dan akan lebih efisien apabila diterapkan pada server 
dengan spesifikasi yang sama dan beban yang juga sama.

\section{TERIMAKASIH}

Terimakasih kepada kemenristekdikti yang sudah membantu mendanai penelitian sebagai penelitian dosen pemula dan juga terimakasih kepada Universitas muhammadiya riau yang sudah memfasilitasi penelitian untuk pengambilan data ini khususnya fakultas ilmu komputer, prodi Teknik Informatika dan Unit Pelaksana terpadu Teknologi Informasi Pangakalan Data (UPT TIPD).

\section{DAFTAR PUSTAKA}

[1] C. M. Babu and O. L. Chandana, "File Transfer Protocol in Cloud Computing," vol. 2, no. March, pp. 665-667, 2014.

[2] I. Santiko and R. Rosidi, "Pemanfaatan Private Cloud Storage Sebagai Media Penyimpanan Data E-Learning Pada Lembaga Pendidikan," J. Tek. Inform., vol. 10, no. 2, pp. 137-146, 2018.

[3] V. K. Reddy and K. T. Rao, "Analysis on Virtualization Technologies in Cloud," vol. 3, no. 7, pp. 2567-2574, 2014.

[4] M. A. Nugroho and R. Kartadie, "Analisis Kinerja Penerapan Container untuk Load Balancing Web Server," JIPI (Jurnal Ilm. Penelit. dan Pembelajaran Inform., vol. 1, no. 02, pp. 7-15, 2016.

[5] M. M. Tajwar, M. N. Pathan, L. Hussaini, and A. Abubakar, "CPU scheduling with a round robin algorithm based on an effective time slice," J. Inf. Process. Syst., vol. 13, no. 4, pp. 941-950, 2017.

[6] Y. L. Oktavianus, "Membangun Sistem Cloud Computing dengan Implementasi Load Balancing dan Pengujian Algoritma Penjadwalan Linux Virtual Server pada FTP Server," J. Nas. Tek. Elektro, vol. 2, no. 1, pp. 25-30, 2013.

[7] G. Thejesvi and T. Anuradha, "Distribution of Work Load at Main Controller Level Using Enhanced Round Robin Scheduling Algorithm in A Public Cloud," Int. J. Comput. Sci. Eng. (eIJCSE 2347-269), no. 12, pp. 75-78, 2015.

[8] A. P. U. Siahaan, "Comparison Analysis of CPU Scheduling: FCFS, SJF and Round Robin," Int. J. Eng. Dev. Res., vol. 4, no. 3, pp. 124-131, 2016.

[9] Y. He, L. Gao, G. K. Liu, and Y. Z. Liu, "A dynamic round-robin packet scheduling algorithm," Appl. Mech. Mater., vol. 347-350, no. Iccsee, pp. 2203-2207, 2013.

[10] L. Fani, I. Ardy, A. Bhawiyuga, and W. Yahya, "Implementasi Load Balancer Berdasarkan Server Status pada Arsitektur Software Defined Network ( SDN )," J. Pengemb. Teknol. Inf. dan Ilmu Komput., vol. 2, no. 5, pp. 2135-2143, 2018. 